\title{
MICROWAVE DETECTION OF SKIN DIELECTRIC PROPERTIES IN SOME LABORATORY ANIMALS
}

\section{Andrew Martusevich ${ }^{1,2} \otimes \mathbb{D}^{\circ}$, Elena Golygina ${ }^{2}$, Artyom Anuchin ${ }^{1}$, Alexander Galka' , Alexander Tuzhilkin', Alexandra Fedotova ${ }^{1}$, Anna Epishkina ${ }^{2}$}

${ }^{1}$ Nizhny Novgorod Agricultural Academy, Nizhny Novgorod
${ }^{2}$ Privolzhsky Research Medical University, Nizhny Novgorod

$\triangle$ cryst-mart@yandex.ru

ABSTRACT - The purpose of this study was a comparative study of the dielectric properties of the integumentary tissues of rats and rabbits. The study allowed to develop standards of basic dielectric parameters and their speciesspecificity for Wistar rats and rabbits.

KEYW ORDS - microwave sensing, skin, rat, rabbit.

Currently, there are numerous medical imaging technologies, but not all biological tissues are covered by their capabilities. So, despite the superficial localization, full visualization of the skin remains a problem $[1,3]$. One of the solutions to this problem is to develop methods for assessing the dielectric properties of the skin [1-3]. In this regard, the purpose of this study was a comparative study of the dielectric properties of the integumentary tissues of rats and rabbits.

\section{MATERIAL AND METHODS}

The dielectric permittivity and conductivity of the skin of 12 rabbits of the breed "Gray Giant" and 25 rats of the Wistar line were studied. The study in all animals was performed at a single point in the middle part of the back. Before the study, the hair in the study area was epilated. The dielectric properties of the skin were evaluated by near-field resonant microwave sensing using a software and hardware complex developed at the Institute of Applied Physics of the Russian Academy of Sciences (Nizhny Novgorod) [2]. The study was carried out with a single sensor with a depth of $5 \mathrm{~mm}$. The data were processed in the package Statistica 6.1. All animal experiments were performed in according to the compliance with EC Directive 86/609/EEC.

\section{RESULTS}

It is established that both studied parameters are species-specific (Fig. 1), and rabbits have both dielectric permittivity and skin conductivity significantly

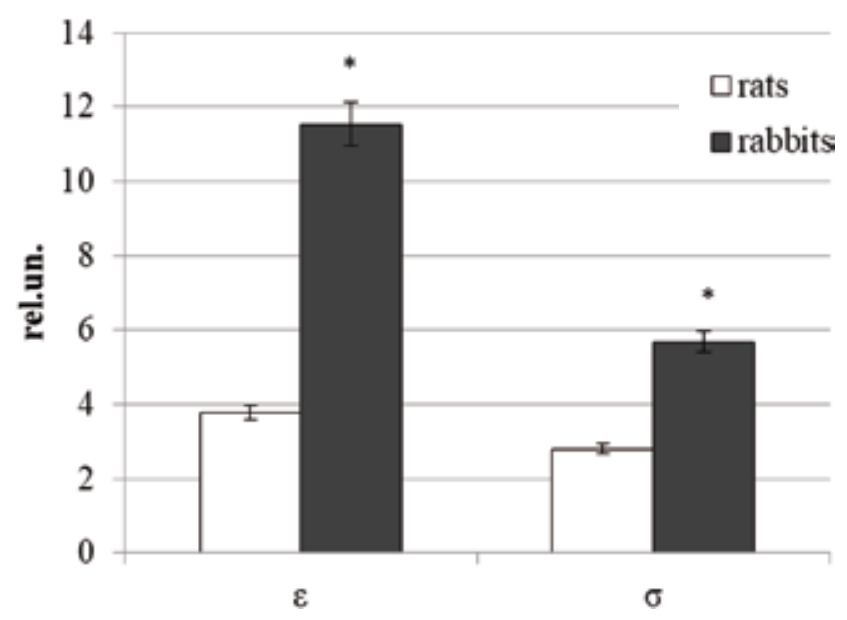

Fig. 1. The level of dielectric permittivity ( $\varepsilon$ ) and conductivity of the skin in rats and rabbits ("**" - level of statistical significance of differences to rats $p<0,05$ )

higher than rats $(\mathrm{p}<0.05)$. This, on the one hand, is due to the specific features of the structure of the skin and subcutaneous structures in the animals under consideration, and, on the other hand, may be due to the uneven thickness of the integumentary tissues in them. Interestingly, in humans, the absolute values of the parameters are significantly higher than in both animal species studied $(\mathrm{p}<0.05$ for rats and rabbits).

\section{CONCLUSION}

Thus, the study allowed to form standards of basic dielectric parameters for Wistar rats and rabbits of the breed "Gray Giant", as well as to demonstrate their species-specificity.

\section{REFERENCES}

1. Hayashi Y., MiUra N., Shinyashiki N., YagiHARA S. Free water content and monitoring of healing processes of skin burns studied by microwave dielectric spectroscopy in vivo // Phys. Med. Biol. 2005. - Vol. 50, N4. - P. N8-N14.

2. Martusevich A.K., Galka A.G., Krasnova S.Yu., Yanin D.V., Kostrov A.V. Comparative study of dielectric properties of the skin of human and laboratory animals // EPJ Web of Conferences. - 2018. Vol. 195. - P. 08004.

3. Raicu V., Kitagawa N., Irimajiri A. A quantitative approach to the dielectric properties of the skin // Phys. Med. Biol. - 2000. - Vol. 45, N2. - P. L1-L4. DOI:10.1088/0031-9155/45/2/101 